\title{
LETTER
}

\section{Minimising drug errors in critically ill patients}

\author{
Andrew Carson-Stevens ${ }^{* 1,2}$, Christopher D Hingston² and Matt P Wise ${ }^{2}$ \\ See related research by Klopotowska et al., http://ccforum.com/content/14/5/R174
}

Klopotowska and colleagues underscore the value of the hospital pharmacists' expertise in reducing medication errors and improving patient safety in critical care [1]. The authors emphasise that drug inaccuracies are frequent and that the limited physiological reserve of critically ill individuals increases the potential harm of adverse prescribing. Critically ill patients represent a unique population with altered pharmacokinetics, and it is likely that the rate of suboptimal prescribing may be even greater than suggested by the current study $[2,3]$. Notably, Klopotowska and colleagues identified that most errors were focused on drug monitoring and suboptimal and incorrect dosing; typically involving antibiotics, drugs used less frequently in critical care and drugs with rapid-change profiles such as anti-thrombotics.

It would have been informative to subcategorise errors by clinical grade (intensivist, fellow, resident); however, it is noteworthy that errors increased during the period with new residents. Training is a central issue because there are features unique to prescribing in this population and residents require additional support. Residents are integral to the processes that underpin many risk factors for medication error [4]. From the outset of their critical care experience, residents are required to prescribe drugs not previously encountered and to chart drugs with unfamiliar routes, rates and indications.

The impact of the limited pharmacy intervention package described in this study [1] could be extended by giving new prescribers an induction focusing on what is unique to critically ill patients. This induction might be delivered as an online resource, undertaken prior to starting in critical care and reiterated as help boxes in electronic prescribing.

\section{Authors' response}

Joanna Klopotowska, Peter Wierenga, Ameen Abu-Hanna, Loraine Lie-A-Huen, Margreeth Vroom and Susanne Smorenburg

We thank Carson-Stevens and colleagues for their useful suggestions to improve medication safety in an intensive care unit (ICU). As Dutch hospital pharmacists have limited time for on-ward activities [1], additional measures are needed to pursue 24/7 medication safety on an ICU. An effective method to define risks and prioritise required measures has been developed in our hospital [5]. Educational interventions such as (online) learning modules for new residents, focusing on pharmacotherapy in critically ill patients, could indeed reduce knowledgebased errors [6]. The continuous change in the ICU patients' clinical conditions, however, necessitates continuous pharmacotherapy evaluation. An audit and feedback on pharmacotherapy by hospital pharmacists could train new residents to cope with such complex

*Correspondence: carson-stevens@doctors.net.uk

${ }^{2}$ Adult Critical Care, University Hospital of Wales, CF14 4XW

Full list of author information is available at the end of the article situations [7]. Based on the expected learning effect, such intensive intervention is needed during the first months of the ICU rotation and could gradually be reduced [1].

Furthermore, for example, standardising prescription of drugs that need frequent monitoring and/or drugs less frequently prescribed in the ICU, and enhancing electronic prescribing by a clinical decision support system (CDSS), could help to cost-effectively minimise skillbased and rule-based errors [6]. The impact of CDSSs in prescribing is especially pronounced in improving adherence to guidelines [8] and could help prevent errors due to drug-drug interactions, overdosing and drugdrug duplications. Such a CDSS is currently under construction in our ICU. A CDSS should, however, be well designed in order to be effective [9].

\section{Abbreviations}

CDSS, clinical decision support system; ICU, intensive care unit.

Competing interests

The authors declare that they have no competing interests. 


\section{Author details}

'Department of Primary Care and Public Health, School of Medicine, Cardiff

University, CF14 4YS, UK. ${ }^{2}$ Adult Critical Care, University Hospital of Wales,

CF14 4XW, UK

Published: 11 January 2011

\section{References}

1. Klopotowska J, Kuiper R, van Kan H, de Pont A, Dijkgraaf M, Lie-A-Huen L, Vroom M, Smorenburg S: On-ward participation of a hospital pharmacist in a Dutch intensive care unit reduces prescribing errors and related patient harm: an intervention study. Crit Care 2010, 14:R174.

2. Taccone F, Laterre P, Dugernier T, Spapen H, Delattre I, Wittebole X, De Backer $D$, Layeux B, Wallemacq P, Vincent J, Jacobs F: Insufficient $\beta$-lactam concentrations in the early phase of severe sepsis and septic shock. Crit Care 2010, 14:R126.

3. Robinson S, Zincuk A, Strøm T, Larsen T, Rasmussen B, Toft P: Enoxaparin, effective dosage for intensive care patients: double-blinded, randomised clinical trial. Crit Care 2010, 14:R41.

4. Moyen $\mathrm{E}$, Camiré E, Stelfox H: Clinical review: medication errors in critical care. Crit Care 2008, 12:208
5. Wierenga PC, Lie-A-Huen L, de Rooij SE, Klazinga NS, Guchelaar HJ, Smorenburg SM: Application of the bow-tie model in medication safety risk analysis consecutive experience in two hospitals in the Netherlands. Drug Safety 2009, 32:663-673.

6. Human Reliability [http://www.humanreliability.com/articles/ Understanding\%20Human\%20Behaviour\%20and\%20Error.pdf]

7. Ostini R, Hegney D, Jackson C, Williamson M, Mackson JM, Gurman K, Hall W, Tett SE: Systematic review of interventions to improve prescribing. Ann Pharmacother 2009, 43:502-513.

8. Eslami S, de Keizer NF, Abu-Hanna A: The impact of computerized physician medication order entry in hospitalized patients - a systematic review. Int Med Inform 2008, 77:365-376.

9. Eslami S, Abu-Hanna A, de Keizer NF, de Jonge E: Errors associated with applying decision support by suggesting default doses for aminoglycosides. Drug Safety 2006, 29:803-809.

doi:10.1186/cc9366

Cite this article as: Carson-Stevens A, et al:: Minimising drug errors in critically ill patients. Critical Care 2011, 15:401. 